\title{
EL ESTADO EN LA PROVINCIA. LA ORGANIZACIÓN INSTITUCIONAL Y ADMINISTRATIVA EN EL NORTE DE CHILE TRAS LA INDEPENDENCIA ${ }^{1}$
}

\author{
Elvira López Taverne \\ Pontificia Universidad Católica de Chile \\ eelopez@uc.cl
}

Este artículo aborda la formación del Estado chileno en una escala local: la provincia de Coquimbo. El objeto de análisis es el proceso de organización institucional y conformación de la administración pública, que ilustra bien los desafios y tensiones inherentes a la construcción estatal en los primeros años de historia republicana.

La relación entre el desarrollo institucional de la provincia y su vocación productiva guía nuestras preguntas, que buscan reconstruir a través de la correspondencia administrativa y la documentación fiscal cómo se articula la incipiente administración local y cuál es su materialidad.

El análisis de la organización institucional y administrativa en Coquimbo ilustrará, de manera representativa, la implementación de las directrices del régimen conservador en las provincias y los instrumentos con que se busca reforzar el control sobre los recursos locales e instaurar un modelo de centralismo económico/administrativo.

PaLABRAS ClaVE: Formación estatal, Chile, Coquimbo, burocracia, prácticas administrativas.

\section{The State in the Province. The institutional and administrative ORganization IN THE NORTH OF CHILE AFTER INDEPENDENCE}

This article addresses the formation of the Chilean State on a local scale: the province of Coquimbo. The object of analysis is the process of institutional organization and conformation of the public administration, which illustrates the challenges and tensions inherent to the State Building in its early years.

1. Este artículo es resultado de la investigación realizada en el marco del proyecto Fondecyt n. ${ }^{\circ} 3160051$.

[Recibido: 1/2/18; Aceptado: 5/6/18] 
The relationship between the institutional development of the province and its productive vocation guides our questions, which seek to reconstruct through administrative correspondence and fiscal documentation how the incipient local administration is articulated and what is its materiality.

The analysis of the institutional and administrative organization in Coquimbo will show, in a representative way, the implementation of the guidelines of the conservative regime in the provinces and the instruments used to reinforce control over local resources and establish a new model of economic / administrative centralism.

KEYWORDS: State Building; Chile; Coquimbo; Bureaucracy.

El objetivo de este artículo es analizar la formación estatal en una escala local: la provincia de Coquimbo. A lo largo de estas páginas se busca estudiar el proceso de organización institucional y conformación de la administración pública, pues sostenemos que este ilustra los desafíos y tensiones inherentes a la construcción estatal en sus primeros años.

El escenario escogido constituye uno de los polos de desarrollo económico, social y político históricos del territorio chileno; la vocación minera de la provincia de Coquimbo es fundamental para el desarrollo institucional de la nueva república, cuya economía se articulará en torno al comercio exterior, que a su vez tiene como base la producción y exportación de minerales. ${ }^{2}$

La relación entre el desarrollo institucional de la provincia y su vocación productiva guía nuestras preguntas, que buscan reconstruir a través de la correspondencia administrativa y la documentación fiscal cómo se articula la incipiente administración local y cuál es su materialidad. Realizar un bosquejo de la estructura administrativa, con sus funcionarios, presupuestos y salarios, nos permitirá observar cuáles son los objetivos primordiales del gobierno, cuál es su capacidad de acción, y cómo las prácticas administrativas se alinean o no con las directrices estatales en una escala local.

2. Marcello Carmagnani ha demostrado como desde el período colonial el Norte de Chile se consolidó como un espacio regional minero. Véase Carmagnani, Marcello, Les mécanismes de la vie économique dans une société coloniale, le Chili: 1680-1830, París, S.E.V.P.E.N., 1973. 


\section{Descripción de la provincia, histórica y geográfica}

Provincia de Coquimbo 1826

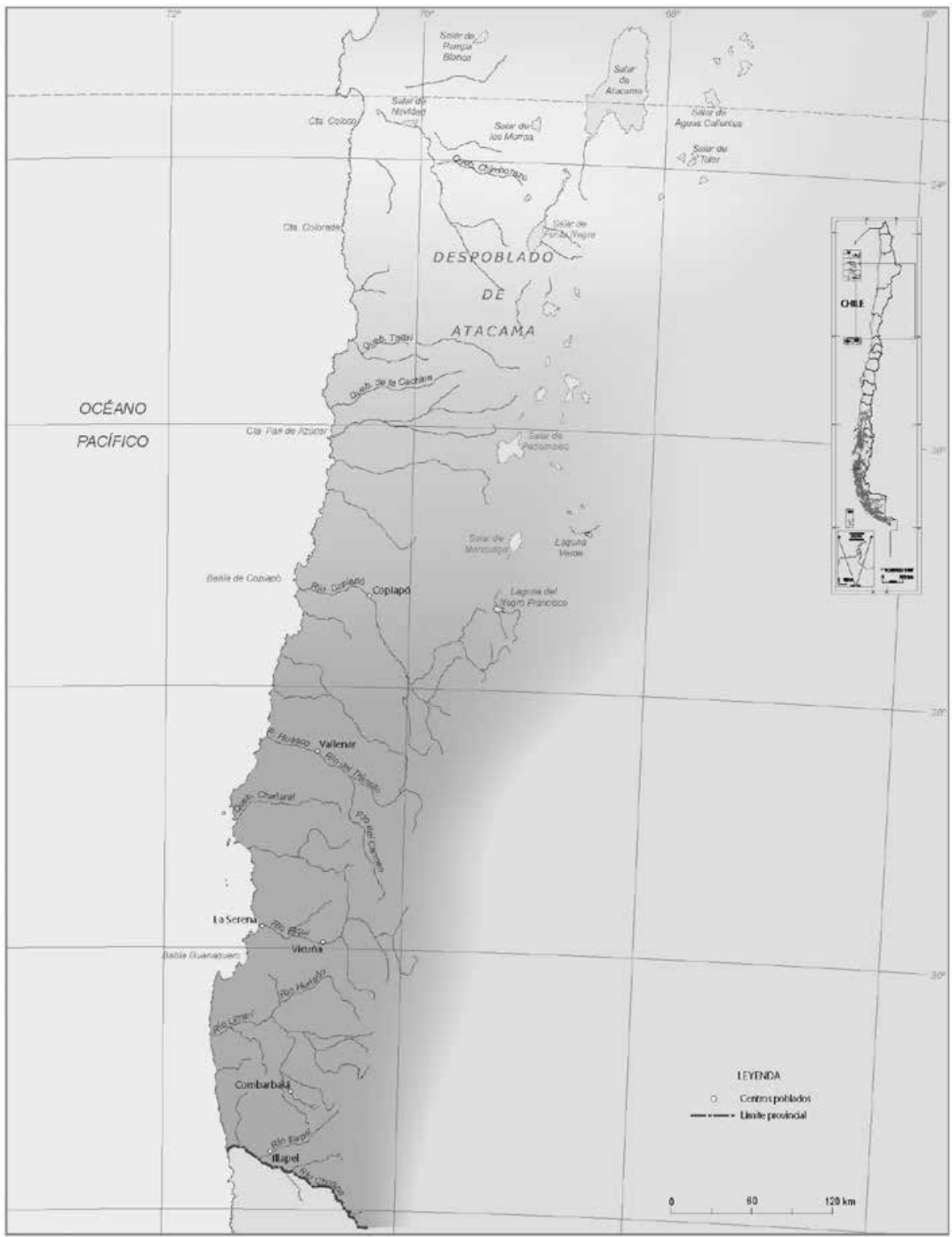

Fuente: Sagredo, González y Compan, La política en el espacio. Atlas histórico de las divisiones político-administrativas de Chile, $1810-19400^{3}$

3. Sagredo, Rafael, González, José Ignacio y José Compan, La política en el espacio. Atlas histórico de las divisiones político-administrativas de Chile, 1810-1940, Santiago, Pontificia Universidad Católica de Chile Instituto Geográfico Militar, Centro de Investigaciones Diego Barros Arana DIBAM, 2016, p. 125. 
La provincia de Coquimbo fue creada como resultado de la división territorial del modelo de Intendencias heredado del régimen colonial. ${ }^{4}$ Las intendencias de Santiago y Concepción se habían establecido en 1786, aunque su aplicación tardó en hacerse efectiva. En 1808, el Cabildo de La Serena propuso la creación de una nueva intendencia en el territorio norte de Santiago, la que será aprobada por el Congreso Nacional en 1811. Su límite septentrional será el desierto de Atacama, llamado el despoblado en ese entonces, en el paralelo 23, y por el sur el río Choapa. ${ }^{5}$

Esta división territorial resultante se condice con la realidad económica, social y política de la gobernación o Reino de Chile, pues desde los tiempos de la Conquista, Coquimbo, Santiago y Concepción constituían polos de desarrollo en torno a los cuales se habían articulado grupos de poder con fuertes intereses locales. ${ }^{6}$

En el caso particular de Coquimbo, la minería constituía la actividad primordial de la región, acompañada en un segundo plano por las actividades agrícolas. Como señala Vicente Pérez Rosales en su Ensayo sobre Chile, «En Chile, como ya lo sabemos, la agricultura y las minas absorben casi exclusivamente los capitales y los brazos de los habitantes».? La primacía de las actividades extractivas queda también reflejada en la información recabada por el naturalista francés Claudio Gay. Según los datos que levantó en 1841, en la provincia se trabajaban 744 minas, de las cuales 499 eran de cobre, 203 de plata y 54 de oro. Respecto al procesamiento de los minerales, se contabilizaron 47 hornos para metal, 39 hornos de reverbero y 80 trapiches. ${ }^{8}$ Una década más tarde un viajero estadounidense describe con entusiasmo las riquezas de la región: «The products of mines in Atacama almost make one believe the genii of Aladdin have still their favored mortal son the earth, one of them having yielded its proprietor within a single year more than half a million of dollars!». ${ }^{9}$

4. Sobre la implantación del régimen de intendencias en Chile véase Cobos, María Teresa, «El régimen de Intendencias en el Reino de Chile. Fase de implantación 1786-1787», Revista Chilena de Historia del Derecho, n. ${ }^{\circ}$ 7, Santiago, 1978, pp. 85-106, y Enríquez, Lucrecia, «Reformar para uniformar. La implantación del régimen de Intendencias en Chile, en Bertrand, M., F., Andújar y T. Glesener (eds.), Gobernar y reformar la Monarquía. Los agentes políticos y administrativos en España y América, siglos XVI-XIX, Valencia, Albatros, 2017, pp. 287-303.

5. Sus principales centros urbanos son Copiapó y La Serena, y los puertos de Huasco, Caldera y Coquimbo. Según el censo de 1843 su población asciende a 103.748 habitantes, lo que ese año representa un 9.7 \% de la población nacional. Cf. Pérez Rosales, Vicente, Ensayo sobre Chile, Santiago, Imprenta El ferrocarril, 1959.

6. Cavieres, Eduardo, La Serena en el siglo XVIII. Las dimensiones del poder local en una sociedad regional, Valparaíso, Ediciones Universitarias de Valparaíso, 1993; Carmagnani, Marcello, El salariado minero en Chile colonial. Su desarrollo en una sociedad provincial: el Norte Chico 1690-1800, Santiago, Editorial Universitaria, 1963; Hurtado, Carlos, Concentración de población y desarrollo económico. El caso chileno, Santiago, Universidad de Chile, 1966.

7. Pérez Rosales, Vicente, Ensayo sobre Chile..., cit.

8. Gay, Claudio, «Questionnaires et réponses sur la situation des provinces du Chili adrésées par Claude Gay aux Gouverneurs», Boite 1: Notes et documents divers, dossier vert: 1841, Mss 096/3/1 à 10, Archives de la Société d'études archeologiques et scientifiques de Draguignan.

9. Giliss, James M., The U.S. Naval Astronomical Expedition to the Southern Hemisphere During the Year 1849-'50-'51-'52, Washington, A.O.P. Nicholson Printer, 1855, p. 244. 
La geografía y el clima del territorio estudiado configuran también el tipo de asentamiento y las características demográficas de su población. Siguiendo estas características, se puede establecer una diferencia entre las dos zonas que la componen y que hoy diferenciamos y conocemos como Norte Grande y Norte Chico. ${ }^{10}$ La primera corresponde a una zona árida y desértica, con solo dos valles irrigados correspondientes a Copiapó y Huasco, donde la población se concentra en las capitales de departamento, en los puertos, o en los improvisados campamentos en torno a los yacimientos mineros. ${ }^{11} \mathrm{La}$ escasez de terrenos aptos para la producción agrícola, y el hecho de que las pocas praderas se ocuparan para alimentar a los animales de carga para el laborío en las minas, conllevó la importación de alimentos tanto desde el resto de la provincia y del país, como desde las provincias trasandinas, particularmente del noroeste, desde donde también se importó ganado mular para el transporte. La segunda región está atravesada por valles transversales aptos para la agricultura, con una dispersión demográfica que se asimila a las características de poblamiento del resto del territorio a principios del siglo XIX.

En la década que sigue a la independencia, la división administrativa del territorio nacional sufrirá importantes transformaciones. De las tres provincias de 1812 (Coquimbo, Santiago, Concepción), su número aumenta a ocho en 1826 (Coquimbo, Aconcagua, Santiago, Colchagua, Maule, Concepción, Valdivia, Chiloé). ${ }^{12}$ En 1833 se añade la provincia de Talca, en 1842 la de Valparaíso; pero lo que resulta más atingente a nuestro estudio es la creación de la provincia de Atacama en 1843. Esta corresponderá a la región septentrional de la antigua provincia de Coquimbo, y contará con los departamentos de Copiapó, Vallenar y Freirina. Coquimbo, por su parte, se subdivide en los departamentos de La Serena, Combarbalá, Elqui, Ovalle e Illapel. ${ }^{13}$

Es posible realizar un bosquejo de la provincia con los datos recabados por el naturalista francés Claude Gay. Entonces compuesta por ocho departamentos (Copiapó, Vallenar, Freirina, La Serena, Combarbalá, Elqui, Ovalle, Illapel), cuenta con 114 establecimientos religiosos en los cuales se desempeñan 65 funcionarios eclesiásticos para curar

10. El desconocimiento del llamado Norte Grande llevó a que en 1853 el gobierno comisionara a R.A. Philippi una misión científica con el objetivo de «conocer la geología de esta parte del territorio y las diferentes especies minerales que puede contener, cuanto para obtener datos geográficos importantes para el conocimiento de esta porción del país», Barros Arana, Diego, El doctor don Rodolfo Amando Philippi. Su vida y sus obras, Santiago, Imprenta Cervantes, 1904.

11. Pérez Rosales menciona que: «La población de Atacama no está tan diseminada como en las provincias australes; a veces la falta de agua y vegetación y más frecuentemente la dificultad de encontrar ocupaciones lucrativas, obligan a los habitantes a agruparse en los valles que riegan los dos pequeños ríos Huasco y Copiapó... Las ciudades principales, los hermosos establecimientos de amalgamación y la mayor parte de los habitantes están agrupados a lo largo de estas dos fuentes de vida, sin las cuales la riqueza mineral de Atacama sería tan estéril como el desierto del mismo nombre», Ensayo sobre Chile..., cit., p. 221.

12. Véase, Sanhueza, María Carolina, «La primera división político-administrativa de Chile, 1811-1826», Historia, vol. 41, n. ${ }^{\circ}$ 2, Santiago, 2008, pp. 447-493; Arias, Karina, «Revisión de las estructuras político-administrativas territoriales en el Chile del siglo XIX», Revista Universum, vol. 1, n. ${ }^{\circ} 25$, Talca, 2010, pp. 44-59.

13. Para una visión gráfica de las subdivisiones del territorio chileno véase, Sagredo, Rafael, José Ignacio González Leiva y José Compan Rodríguez, La política en el espacio..., cit. 
las enfermedades del alma. ${ }^{14}$ Tocante a las enfermedades físicas, hay un total de 9 médicos y cirujanos, aunque se distribuyen únicamente en Copiapó y Vallenar. Las principales enfermedades son las fiebres y disenterías. Para la vigilancia y cuidado de la población se cuenta con 21 miembros de policía de dependencia municipal, quienes entre sus deberes deben cuidar de los 709 presos contabilizados por año, de los cuales 80 fueron por asesinato entre 1830 y 1840 . Sobre la alimentación, se prioriza el consumo de ovejas y carneros (935 diarios) por sobre el de vacunos (31 diarios). Las características geográficas y climáticas antes descritas inciden en el elevado costo de la vida en las provincias del norte, hecho constatado por los funcionarios públicos que reclaman de esta situación. ${ }^{15}$ Finalmente, respecto a la demografía de la región, según el censo de 1813 la población asciende a 43.449 habitantes, ${ }^{16}$ y en 1843 se eleva a 103.679. En 1842 esta se distribuye en 1842 en 38 pueblos con 133.391 casas en la superficie de la provincia. ${ }^{17}$

En 1853, el gobierno chileno encarga la primera exploración científica del desierto de Atacama al naturalista alemán Rudolph Philippi, quien describe su llegada a Coquimbo como sigue:

El puerto de Coquimbo es uno de los mejores de Chile, pero la población constaba entonces apenas de unas cien casas y ranchos, de una pequeña capilla y de los dos establecimientos de los señores Edwards y Lambert para la fundición de los metales de cobre... Confieso que las casas pobres de la población, las colinas sumamente áridas cubiertas de poca vegetación que la respaldan, los cerros desnudos parduscos que se ven más lejos y la playa pelada que se extiende por leguas a la izquierda no me dieron una impresión agradable, pero el aspecto de los

14. Los establecimientos corresponden a conventos, iglesias, capillas y oratorios; y los funcionarios eclesiásticos a curas, sotacuras, clérigos y religiosos.

15. El costo de la vida varía de una provincia otra; en el norte los alimentos son más caros, mientras que el costo de la vivienda es más elevado en ciudades como Santiago y Valparaíso, aunque la oferta es también más variada. Si tomamos como referente el sueldo de los intendentes y los precios relevados por Claudio Gay (ver misma nota), podemos deducir que el sueldo en La Serena tenía un poder adquisitivo equivalente al $42 \%$ del de Valparaíso (si el costo era similar que en Santiago) y el de Valdivia, al $58 \%$.

Los precios de los alimentos provienen de un cuestionario realizado por Gay. Las preguntas n. ${ }^{\circ} 26,27$ y 28 preguntan respectivamente por el precio regular de una cabeza de ganado, el de una de oveja o carnero, y el de una gallina. De sur a norte los precios son: en el departamento de Castro (Chiloé): 5/6 pesos; $4 / 6$ reales; 1 real. En Valdivia: 9 pesos; 1 peso; 2 reales. En Chillán: 10/17 pesos; 6/8 reales; 1 real. En Talca: 13/15 pesos; 5/8 reales; 1 real y cuartillo. En Santiago: 13/14 pesos; 8/10 reales; 2 reales. En La Serena: 20 pesos; 12 reales; 3 1/2 reales. En Copiapó: 2 onzas de oro selladas una vaca; $3 / 4$ pesos; 1 peso. Claudio Gay, «Questionnaires et réponses...», cit.

La mención de un funcionario público de aduanas sobre las fluctuaciones de precios entre las provincias, en Archivo Nacional de Chile, Fondo Ministerio de Hacienda (en adelante AMH), vol. 28, s/fj. Santiago 4 de julio de 1835 .

16. Censo de 1813 levantado por don Juan Egaña, de orden de la Junta de Gobierno, firmada por los señores Pérez, Infante y Eyzaguirre, Santiago, Imprenta Chile, 1953. Las cifras y estadística de la época son bastante imprecisas, véase Estefane, Andrés, «Un alto en el camino para saber cuántos somos. Los censos de población y la construcción de lealtades nacionales. Chile, siglo XIX», Historia, n. ${ }^{\circ}$ 37, vol. 1, enero-junio, Santiago, 2004, pp. 33-59.

17. Según los datos del censo de 1843 procesados por Vicente Pérez Rosales, el 74,8 \% de la población habita en las provincias del centro, un 15.4 \% en el sur, y solo un 9,7 \% en el norte. Véase, Pérez Rosales, Vicente, Ensayo sobre Chile..., cit., pp. 233-234. 
edificios blancos y resplandecientes de La Serena, capital de la provincia, que dista sólo unas dos leguas, es muy halagüeño. ${ }^{18}$

Su opinión del puerto de Caldera no es mucho más auspiciosa, «el puerto es muy seguro y excelente, pero sus contornos son sumamente tristes». ${ }^{19}$ Es la falta de vegetación lo que al parecer aflige al viajero: «Se ve una playa arenosa baja y desnuda y a la distancia cerros enteramente pelados; el ojo, por más que busque, no encuentra un solo árbol, un solo arbusto». ${ }^{20}$ No obstante, el asentamiento le causa mejor impresión «Las casas de la población son en general bonitas y hay muchos edificios grandes de buena apariencia», ${ }^{21} \mathrm{al}$ igual que el valle y pueblo de Copiapó en razón de su fertilidad y gran variedad de cultivos y huertos.

\section{La década de 1820: administrar y organizar en tiempos de conflicto}

La organización política y administrativa de la provincia vivió tiempos convulsos en la primera década independiente. El período de aprendizaje político ${ }^{22}$ está marcado por los estertores de la guerra de independencia que afectan de manera directa a la región. La crisis económica y productiva hace estragos en las arcas provinciales que no dan abasto a los requerimientos de la capital. Santiago apremia por recursos para financiar las distintas campañas militares, contra los realistas, la campaña de Liberación del Perú, la de Valdivia y Chiloé, y contra las montoneras realistas. ${ }^{23}$

Estos factores condicionan las relaciones entre Coquimbo y las otras dos provincias históricas de Santiago y Concepción. ${ }^{24}$ La discusión en torno al modelo político-administrativo a implementar conlleva una tensión constante, y el modelo de ensayo-error tiene un impacto directo en el «desorden» político que se refleja a nivel administrativo local. La estructura de la administración provincial es altamente inestable en la primera década independiente (1818-1829). La indefinición sobre el modelo político-administrativo proviene de la falta de consenso en torno al modelo político nacional; los sucesivos textos constitucionales de los años veinte oscilan entre el ideario federal y un acentuado centralismo. ${ }^{25}$

18. Philippi, Rudolph, Viaje al desierto de Atacama, Santiago, Cámara Chilena de la Construcción, Pontificia Universidad Católica de Chile, Biblioteca Nacional, 2008 [1860], p. 11.

19. Philippi, Rudolph, Viaje al desierto..., cit., p. 13.

20. Ibidem, p. 13.

21. Ibidem, p. 13.

22. Heise, Julio, Años de formación y aprendizaje políticos 1810-1833, Santiago, Editorial Universitaria, 1978.

23. Salazar, Gabriel, Mercaderes, empresarios y capitalistas (Chile, siglo XIX), Santiago, Editorial Sudamericana, 2009.

24. Cartes, Armando, «Un gobierno de los pueblos...». Relaciones provinciales en la independencia de Chile, Valparaíso, Ediciones Universitarias de Valparaíso, 2014.

25. El período entre la caída de Bernardo O’Higgins en 1822 y la guerra civil de 1829 fue denominado como «anarquía», y hoy en día se conoce como el período de los «ensayos constitucionales», y se caracteriza por 
Si bien los cambios a nivel legislativo no siempre se condicen con la realidad local, que a veces se mantiene incólume, el desorden administrativo y documental evidencia que estamos frente a un proceso de formación burocrática en ciernes. Por ello es complejo reconstruir una estadística y jerarquías claras, ya que en numerosas ocasiones los mismos funcionarios no tienen claras sus facultades, su jurisdicción, ni su línea de mando. El número de empleados públicos tampoco se detalla en los presupuestos, y es indirectamente a través de los decretos de nombramientos, renuncias, y otra documentación que se puede reconfigurar el entramado de la burocracia local.

La administración local está compuesta por elementos institucionales coloniales que siguen vigentes, por decretos ejecutivos, por leyes y reglamentos legislativos, y también por reglamentos del ejecutivo de la provincia, que en algunos años corresponde a la Asamblea Provincial, y no a la autoridad representante del gobierno central en la provincia, vale decir el intendente. ${ }^{26}$

En la década de 1820 el organigrama es el siguiente: a la cabeza de la provincia figura el gobernador intendente, secundado por los tenientes gobernadores de Copiapó, Vallenar, Elqui, Combarbalá e Illapel. La secretaría de la capital provincial cuenta con dos oficiales y las demás gobernaciones con un secretario u oficial (en ocasiones el mismo escribano del cabildo). ${ }^{27}$

En las reparticiones de Hacienda, tras la independencia, la administración de alcabalas de Coquimbo accedió al rango de aduana general.

CuAdro 1. Funcionarios de la Aduana General de Coquimbo, año 1825

\begin{tabular}{llc}
\hline \multicolumn{1}{c}{ Nombre } & \multicolumn{1}{c}{ CLASE } & DOTACIÓN (pesos anuales) \\
\hline Custodio Amenábar & Ministro tesorero & 1.500 \\
Antonio Cordobés & Ministro contador & 1.500 \\
José Vicente Castellón & Vista y primer oficial & 800 \\
José Gregorio Meri & $2 .^{\circ}$ oficial & 500 \\
Eulogio Castro & 3. oficial $^{\circ}$ & 300 \\
Rafael Morgado & $4 .^{\circ}$ oficial & 300 \\
Lorenzo Veliz & Portero & 100 \\
\hline
\end{tabular}

FuENTE: AMH, vol. 46, Coquimbo 19 de enero de 1825, sin foja.

una inestabilidad política y una fuerte crisis económica. Véase Collier, Simon, Ideas y política de la independencia chilena, 1808-1833, Santiago, Fondo de Cultura Económica, 2012.

26. Las asambleas provinciales, autoproclamadas y constituidas en autoridades ejecutivas, también cumplen funciones legislativas y judiciales de facto; nombran funcionarios, establecen la formación de una biblioteca y otras obras públicas, ejercen la administración de justicia en la provincia, establecen un tribunal de minería, reorganizan instituciones educativas, etc. Cabe señalar que varios miembros de los cabildos locales fueron elegidos como representantes en dichas asambleas, Archivo Nacional de Chile, Fondo Municipalidad de Coquimbo, vol. 2.

27. Véase por ejemplo el caso de Vallenar en Archivo Nacional de Chile, Fondo Intendencia de Coquimbo (en adelante A.N.I.C.), vol. 7, Vallenar 20 de octubre de 1817, s/foja. 
A la oficina fiscal de Coquimbo se añaden las de Copiapó y Huasco, conformadas por un ministro de aduana y un oficial (pueden ser dos). Además de un administrador de alcabalas con subalternos en las villas principales y en las gobernaciones. Las aduanas cuentan con un Resguardo, compuesto por un comandante y un grupo de soldados o guardas. En el caso de Coquimbo, se desempeñan allí un comandante, un cabo, nueve guardas y dos guarda-botes. ${ }^{28}$ En la década de 1820 opera también una Casa de Moneda, aunque las constantes quejas y reglamentos en torno a ella ponen en cuestión su real funcionamiento.

Las aduanas y tesorerías formaban una misma institución, encargada de controlar y regular el comercio (exterior e interior) y de cobrar impuestos, funciones que se separarán con el paso del tiempo. La tendencia será disminuir las numerosas partidas que constituían pequeñas entradas para el fisco, privilegiando las rentas de mayor cuantía; $;{ }^{29}$ al tiempo que el desarrollo espectacular del comercio exterior ${ }^{30}$ y el creciente peso de su impuesto en la estructura del ingreso fiscal implicará una fuerte transformación respecto de la estructura impositiva colonial. Ambos elementos repercuten en el protagonismo que cobrarán las oficinas de aduanas en el corto y largo plazo.

Referido a la administración judicial, la provincia cuenta solo con un juez de letras. Sin embargo, el reglamento de 1824 reconocía como funcionarios subalternos a los inspectores de distritos, a los subdelegados y a los alcaldes de primer voto en las villas cabeceras. ${ }^{31}$ Esta convivencia entre dos esquemas de administración de justicia, una colonial y otra republicana, conlleva numerosas querellas en torno a la jurisdicción y facultades que tienen las autoridades para levantar causas, llevar procesos e impartir justicia; los límites son imprecisos y en ocasiones la tradición jurídica colonial confronta las atribuciones de los nuevos funcionarios republicanos. ${ }^{32}$

Si bien esta estructura administrativa es precaria, las autoridades pueden sortear los problemas que se presentan justamente porque hay una maleabilidad y una capacidad de

28. A.M.H., vol. 46, Coquimbo 19 de enero de 1825, sin foja.

29. La estructura de los impuestos no varió mucho tras la independencia. Hasta la década de 1850 las rentas se siguen clasificando en contribuciones directas, indirectas, monopolios y rentas eventuales. Las entradas directas comprenden aquellas que afectan a la propiedad y las personas (contribución territorial, catastro, derecho sobre imposición de capitales, patentes, y peajes). Las rentas indirectas incluyen los derechos de aduana (importación y exportación), y los derechos de almacenaje, faro, muelle, tonelada y remolque. Los monopolios comprenden las especies estancadas, tabaco, naipes y papel sellado. Finalmente, los ramos eventuales corresponden a las rentas provenientes de la venta de terrenos fiscales. Véase, Anuario Estadístico de la República de Chile, tomo III, p. 119.

30. El término «desarrollo espectacular» lo tomamos de Gabriel Salazar.

31. Consultar Bilot, Paulina, «Las causas por torcida administración de justicia: mirada letrada hacia prácticas legas en Chile, 1824-1875», SudHistoria, n. ${ }^{\circ}$ 5, julio-diciembre, Chile, 2012, pp. 99-123; Enríquez, Lucrecia, «Los jueces diputados y los distritos judiciales borbónicos en Chile (1786-1818)», Revista Chilena de Derecho, vol. 43, n. ${ }^{\circ}$ 2, Santiago, 2016, pp. 643-668.

32. Véase la disputa entre el teniente asesor letrado de Coquimbo y el teniente gobernador de Huasco en la causa criminal contra José María Quevedo. A.N.I.C. vol. 13, 26 de febrero de 1821, s/foja; o la comunicación del delegado de San Isidro de Vicuña, quien comunica al intendente desconocer las atribuciones y el grado de extensión de las facultades del juez de letras de Coquimbo, señalando además que la Constitución no indica sus facultades, A.N.I.C. vol. 14, San Isidro de Vicuña 9 de agosto de 1824, s/foja, firma Santiago Iglesias. 
ajuste que se condice con el reducido margen de acción que tienen las mismas autoridades. El sistema político cambia, pero en la provincia las cosas no cambian mucho. La numerosa correspondencia de las autoridades subalternas al intendente, en la que solicitan información sobre cuáles son sus funciones y su jurisdicción, es un ejemplo decidor. También son recurrentes las peticiones para que se les envíe material legislativo: reglamentos, constituciones, el diario oficial. El congreso dirime asuntos y promulga leyes que pueden tardar muchísimo o no llegar nunca a ser conocidas por las autoridades de los lugares más remotos.

No obstante, la misma documentación muestra que subyace una cierta estabilidad en el día a día, la capacidad de administrar y de resolver conflictos no se ve mermada, pese a las constantes quejas por la precariedad y la falta de recursos. El reducido tamaño de la burocracia local puede ser un factor que explique este fenómeno, al igual que la permanencia de vínculos entre los funcionarios y la élite local, o el que muchos sean oriundos de la provincia. ${ }^{33}$ En efecto, las autoridades subalternas como los tenientes gobernadores son miembros notables del pueblo o villa, por lo que operan como bisagras entre las demandas de la sociedad local y el Intendente provincial, que representa a la autoridad central. Del mismo modo, vista la precariedad en materia de justicia, por ejemplo, estas atribuciones siguen en manos de los cabildos, por lo tanto de miembros locales.

La década de 1820 es justamente un escenario de adaptación, en el que perviven no solo prácticas «tradicionales» sino que la estructura administrativa no se ha reformado enteramente. En materia de hacienda, por ejemplo, aunque la estructura impositiva cambia radicalmente, solo se efectúan reformas mayores tras la visita fiscal de 1831, sobre la que nos detendremos a continuación.

Asimismo, la precariedad y falta de recursos que afecta a la administración local no se condice con la riqueza de la provincia. De hecho, en 1826 la Asamblea Provincial contrató de manera autónoma, aunque negociando con el Intendente Francisco Antonio Pinto, un empréstito de 120 mil pesos para financiar la campaña que terminaría definitivamente con la presencia realista en la isla de Chiloé. ${ }^{34}$ Para ello se negoció un contrato en el que el gobierno solicitaría a la Asamblea la exportación libre y franca de pastas de plata en los puertos habilitados de la provincia, y los exportadores deberían de pagar cuatro reales en marco, monto que iría a las arcas provinciales. El gobierno central se vio en la difícil situación de aceptar el contrato, ya que necesitaba esos recursos de manera urgente, aunque señaló expresamente que fijar los derechos de exportación era una atri-

33. La pervivencia de elementos «tradicionales» en la administración republicana es un tema a debatir, aunque autores como Jacques Barbier han apuntado a la resistencia que ejerció la élite local, en el caso chileno, a las reformas administrativas borbónicas a fines del período colonial. En efecto, producto del esfuerzo reformista se crearon muchos nuevos puestos, pero gran parte de los nuevos oficiales se casaron localmente, fortaleciendo los vínculos entre los funcionarios reales y las élites coloniales. Véase, Barbier, Jacques, «Elite and Cadres in Bourbon Chile», The Hispanic American Historical Review, vol. 52, n. ${ }^{\circ}$ 3, Washington DC, 1972 , p. 425.

34. El empréstito se negoció con el gerente de la Chilean Mining Association, Carlos Lambert. Véase, Ossa, Juan Luis, «La actividad política de Francisco Antonio Pinto: 1823-1828. Notas para una revisión biográfica», Historia, n. ${ }^{\circ}$ 40, vol. 1, enero-junio, Santiago, 2007, pp. 91-128, p. 109. 
bución del gobierno central. De esta situación se puede inferir que la existencia de un puerto aduanero otorgaba una relativa autonomía fiscal a la provincia, autonomía que tras la instauración del régimen conservador en 1830 se buscará eliminar.

\section{Visita fiscal a la provincia de Coquimbo}

Tras la guerra civil de 1829, el gobierno ordena una visita fiscal a la provincia de Coquimbo. Este recurso era un instrumento de control administrativo colonial que permitía conocer la realidad y el funcionamiento local de las oficinas de hacienda, y en general se realizaban en contextos de cambio gubernamental o con antelación a transformaciones de orden burocrático. En este caso en particular, el objetivo es poner fin al abandono en que se hallan las oficinas fiscales, y en palabras de Victorino Garrido, el visitador, su misión estuvo motivada por el desorden y la falta de régimen y buena administración que causaba perjuicios al erario público. ${ }^{35}$

Producto de la visita el presidente de la república propone al Congreso un proyecto de reforma de las oficinas fiscales en el que se detallan las directrices económicas, fiscales y administrativas del gobierno. Por otra parte, en la correspondencia entre el visitador y el ministro de Hacienda destacan de forma recurrente tres elementos: la pobreza, la infraestructura deficiente, y el desorden de las finanzas locales. Cabe destacar que para las autoridades locales y centrales estos elementos se encontraban relacionados.

Respecto a la infraestructura, en el caso de Coquimbo el resguardo no cuenta con un bote «ni embarcación alguna», indispensables para el desempeño de sus funciones. La capitanía del puerto se halla en las mismas condiciones, «no hai quien la sirva». ${ }^{36} \mathrm{La}$ situación se repite en el puerto de Huasco y Copiapó. Allí la responsabilidad recae en guardas que deben su nombramiento a autoridades subalternas, y que además cuentan con el «corto y miserable» sueldo de treinta pesos mensuales, estipendio que no les permite mantener las cabalgaduras. A Garrido le resulta evidente que esto contribuye y estimula el contrabando. ${ }^{37}$

El desorden en la gestión de las rentas fiscales, por su parte, impide establecer el monto de la deuda pública en la provincia, «pues como ya he manifestado a V.S..., la oficina de esta Aduana y Tesorería de esta ciudad, ha estado tan mal servida que son muy pocos los datos que se pueden adquirir, y esto a costa de infinitas dificultades. ${ }^{38}$ Las constataciones de este orden van a generar tensiones con los funcionarios locales, pues los

35. AMH, vol. 74, Santiago, junio 4 de $1830 \mathrm{~s} / \mathrm{f}$.

36. Garrido, Victorino, «La Serena, Julio 22 de 1830», en AMH, vol. 74, s/f.

37. «Es así evidente, que un sueldo tan módico, o mas bien ridículo, lejos de una retribucion suficiente para subvenir a la subsistencia en lugares tan escasos de recursos, solo habra servido para aumentar el cumulo de perjuicios que debe haber experimentado el fisco en la exportacion de materias de muy poco bulto y facil ocultacion, como son generalmente los metales, y particularmente el de plata». Victorino Garrido, «La Serena, 6 de Octubre de 1830», en AMH, vol. 74, s/fj.

38. Victorino Garrido, «La Serena, Julio 22 de 1830», en AMH, vol. 74, s/f. 
poderes otorgados a Garrido lo constituyen en el jefe superior de la institución en la que se encuentra.

Un suceso de esta índole ocurre en la aduana de La Serena; el visitador ordena no efectuar ningún pago sin su autorización, lo que es incumplido. Para evitar que se produzcan nuevas malversaciones, dado «el abandono con que se han manejado para la organización de sus cuentas», ${ }^{39}$ Garrido arresta a los ministros en su lugar de trabajo, una práctica recurrente para no detener el arreglo de las cuentas. Pero los funcionarios ocultan datos y destruyen los libros para evitar la formulación de cargos. Pese a la gravedad de la falta, el visitador no presenta una causa formal en el juzgado de letras, pues teme que esta acción conlleve la suspensión de los acusados y el nombramiento de individuos que desconoce, y que podrían ser aún más incompetentes. También podemos conjeturar que se trata de una «depuración política» de elementos contrarios al nuevo régimen conservador.

El veredicto del informe final será por ello tajante, el visitador propondrá una «reforma radical» para mejorar el «estado de inercia y abandono» en que a su juicio se hallan los ramos de hacienda; «no hay mas recurso que rehacerlo todo y arreglarlo bajo un sistema absoluto de regeneración». ${ }^{40}$

Con este documento como base, el Ejecutivo presenta al Congreso un plan para la reforma de las oficinas fiscales en septiembre de $1831 .{ }^{41}$ Entre sus varios puntos se contempla:

- Nuevo organigrama de empleados y salarios.

- Solicitud para que las aduanas de Huasco y Copiapó pasen de subalternas a principales.

- Incorporación de las tenencias de ministros de Huasco y Copiapó a las aduanas. ${ }^{42}$

El nuevo plan de funcionarios y salarios es justificado por el mismo Garrido:

En todo lo demás del plan, me he ceñido a lo puramente necesario, consultando las localidades, teniendo presente la carestía de víveres i otros artículos de primera necesidad en aquellos puertos, i cuántas circunstancias pueden influir en el método i regularidad con que deben

\section{Ibidem.}

40. Victorino Garrido, «La Serena, 20 de Setiembre de 1830» en AMH, vol. 74, s/fj.

41. «Sesión del 19 de agosto de 1831», en Letelier, Valentín, Sesiones de los Cuerpos Legislativos de la República de Chile 1811 a 1845 (en adelante SCL), Santiago, Imprenta Cervantes, 37 tomos, 1887-1908, tomo XX, pp. 283-285.

42. «Reducidas las tenencias de Ministros de Huasco i Copiapó a un estado casi completo de nulidad, he creido conveniente agregar estas oficinas a las aduanas de aquellos departamentos, según verá V. S. en el espresado plan. Ambas tenencias de Ministros han dejado de ser recaudadores, desde que el papel sellado i patentes se espenden por las administraciones de especies estancadas, i han sido devueltos los bienes de regulares. Los pagos que por ellas se hacen son rarísimos i de mui cortas cantidades, i como para esto considero supérfluas cuatro oficinas, he conceptuado que pueden desempeñarse por los administradores de aduanas las tesorerías sin ningún perjuicio fiscal, i bajo de fianzas que, como administradores independientes, deben de dar a satisfacción de la Comisión de Cuentas». Letelier, Valentín, Sesiones de los Cuerpos..., cit. 
quedar establecidas las tres aduanas. Con concepto a esto, he fijado los sueldos de los empleados i el número de ellos... ${ }^{43}$

Respecto a los salarios, destaca que hay un aumento entre la inversión actual y la propuesta. No obstante, esta «debe considerarse sumamente pequeña, si la comparamos con los grandes bienes de que participará el comercio i los grandes fraudes que se le evitarán al Fisco»; vale decir, el crecimiento de los ingresos costeará la diferencia. Pero además apela a un cambio de mentalidad, llama a aplicar la lógica de los comerciantes particulares, «... que gastan en los primeros años para su seguridad i cultivo, lo que vienen a recojer con usura después de tenerlas arregladas». ${ }^{44}$ Las autoridades se deben convencer de la necesidad de imitarlos, «i de invertir las sumas precisas para crear unas oficinas que hoi existen en un modo imperfecto i que, dentro de mui poco tiempo, se considerarán como las primeras i principales fuentes de la riqueza nacional». ${ }^{45} \mathrm{La}$ situación política y económica ha cambiado y no se puede continuar con la planta de funcionarios de cuando «Chile era una colonia i su comercio no proporcionaba ni aun las entradas necesarias para señalar sueldos a los empleados». ${ }^{46}$

En cuanto al segundo punto, el cambio de estatus de las aduanas subalternas a principales se debe a «los progresos que ha hecho el comercio de pocos años a esta parte, que por si sólos bastarían para dar nueva planta a las dos aduanas», además de otros más prácticos como la enorme distancia que existe entre las oficinas subalternas y Coquimbo (55 leguas), lo que dificulta el manejo a la distancia. Por último, reorganizar las jerarquías implica prevenir malversaciones y perjuicio a los intereses fiscales.

El tercer aspecto, la incorporación de las tenencias de ministros a las aduanas, se justifica por el estado «casi completo de nulidad». Las tenencias de ministros formaban parte de las tesorerías, instituciones encargadas de cobrar distintos tributos pero que fueron perdiendo su utilidad cuando el régimen comenzó a eliminar tributos con baja recaudación y comenzó a potenciar las oficinas de aduana. Las tesorerías provinciales habían dejado de recaudar impuestos ya sea porque se había delegado a otra institución o se había suspendido el impuesto en cuestión (como el caso de los bienes de regulares que fueron devueltos). «Los pagos que por ellas se hacen son rarísimos i de mui cortas cantidades», no siendo necesario contar con cuatro oficinas. El visitador propone que sean las aduanas quienes asuman esta función, y que respondan ante el Tribunal de Cuentas.

Es interesante observar los argumentos de Garrido tocantes a la defensa de los intereses fiscales, pues se contraponen a los que esgrimen las autoridades a la hora de reorganizar la administración interior de la República. En efecto, se justifica la existencia de tres aduanas principales en la provincia, y no dos subalternas dependientes de Coquimbo,
43. Ibidem.
44. Ibidem.
45. Ibidem.
46. Ibidem. 
pues si el administrador principal fuese un estafador, «¿qué de perjuicios no se le seguirían?». El funcionario subalterno que no fuere dependiente o cómplice sería «indefectiblemente depuesto i sustituido por otro que correspondiese a los depravados fines del que le había nombrado, i podía removerle con el solo acto de dar parte al Gobierno, diciendo que tal funcionario no merecía su confianza». ${ }^{47}$

Pero solo dos años después de presentado el Plan de Hacienda se reformará la administración interior del territorio de la República bajo un sistema altamente vertical y centralizado. El presidente de la República se ubica en la cima, y designa directamente a los intendentes y gobernadores de plaza (Constitución, 1833: art. 82, 6a). El territorio de la República se divide en provincias, departamentos, subdelegaciones y distritos (artículo 115). El gobierno de la provincia queda en manos de un intendente, quien gobernará «con arreglo a las órdenes e instrucciones del presidente de la República, de quien es ajente natural e inmediato» (Constitución, 1828: art. 110, 113), y puede ser reelegido para el cargo infinitas veces. La dirección de los departamentos se otorga a los gobernadores, quienes también son nombrados por el presidente a propuesta de los intendentes. Y por último, los subdelegados a cargo de las subdelegaciones y los inspectores a la cabeza de los distritos son nombrados por sus respectivos superiores. Se configura así un entramado jerárquico que depende directamente del Ejecutivo.

La nueva jerarquía es justificada por Andrés Bello, uno de los intelectuales que participaron en la redacción de la Constitución:

Elegidos los intendentes por las asambleas, y los gobernadores departamentales por los cabildos, faltaba aquella dependencia sucesiva y continuada por la cual el jefe de la república puede hacer efectiva la responsabilidad de todos los agentes de la administración. Antes eran unos funcionarios aislados que podian entregarse a toda clase de extravios, fundados en que no podían ser destituidos por su jefe superior; pero ahora que por la reforma se ha establecido que sean nombrados y destituidos por el Presidente de la República, tienen precisión de ser más exactos en el cumplimiento de sus deberes y muy pocos medios de sobreponerse a ellos. ${ }^{48}$ [destacado del autor]

Distanciadas por solo dos años, las reformas a la organización de las oficinas de hacienda y de la administración interior despliegan una argumentación contradictoria. En el primer caso se postula que la dependencia jerárquica y centralización de todas las oficinas fiscales ante Coquimbo puede inducir o agravar la evasión o fraude al fisco. En el segundo caso, la centralización y jerárquica vertical prevendría los extravíos.

Esta distancia puede responder al objetivo de cada reforma; incrementar la recaudación fortaleciendo la institucionalidad económica y comercial local, y por otra parte afianzar el control político y social del gobierno central en las provincias.

\section{Ibidem}

48. Bello, Andrés, El Araucano, n. ${ }^{\circ}$ 140, 141 y 142 (editorial), en Sagredo, Rafael (ed.), Textos fundamentales. Construcción del Estado en Chile, Andrés Bello, Santiago, Cámara Chilena de la Construcción, Pontificia Universidad Católica de Chile, Biblioteca Nacional, Biblioteca Fundamentos de la Construcción de Chile, 2010, p. 193. 
Ahora bien, cabe preguntarse por la particularidad de Coquimbo respecto al resto de las provincias que conforman la República. La visita fiscal permite establecer una comparación en el sentido de que únicamente tres provincias contaban con una estructura administrativa propiamente tal, tanto por su tamaño como por la existencia de un entramado institucional en las tres áreas principales de gobierno (administrativa, económica y judicial). Dejando de lado el caso de Santiago, capital cuya preponderancia resulta evidente, la provincia de Concepción representa la contraparte «natural» de Coquimbo. Sin embargo, en ese territorio se peleó la guerra de Independencia, con costos económicos y sociales enormes. El estado crítico en que dichas campañas dejaron a la economía local es destacado en la correspondencia del general Ramón Freire a O’Higgins: la destrucción de las cosechas, carestía y hambruna, son flagelos constantes.$^{49}$ La recuperación económica y la rearticulación de la provincia será un proceso lento, y se refleja en la administración. El visitador señala que en Concepción su labor fue menos efectiva, por el desorden administrativo y puesto que recién se removió la aduana desde la ciudad al puerto. La recuperación económica de la región tendrá que esperar hasta la década de 1840, cuando la producción local de cereales encuentre un nicho en los recientes mercados de California y Australia. ${ }^{50}$

La preocupación de las autoridades centrales está sin embargo puesta en Coquimbo; cabe recordar que en un principio la visita fiscal fue destinada únicamente a esta provincia. Asimismo, los reglamentos y la legislación en materia económica y fiscal tocante a ella son notoriamente más numerosos que los referidos al resto, si descontamos el puerto de Valparaíso (dependiente de Santiago). Este interés, que se manifiesta también en el encargo de misiones científicas para conocer su territorio (Claudio Gay, Ignacio Domeyko), demuestra que los gobernantes eran conscientes del rol clave que jugaba la minería para el desarrollo económico nacional. Pero no solo las autoridades nacionales eran conscientes de ello, los cónsules británicos y su delegado comercial en Coquimbo no cesan de enviar información sobre la producción minera de la región y el consumo local de productos ingleses. ${ }^{51}$

En el período estudiado, Manuel Llorca-Jaña apunta que entre 1818 y 1830 el puerto de Coquimbo exportó un promedio de $£ 140.000$ en metales preciosos cada año, ${ }^{52}$ cifra que no contempla los grandes montos del contrabando. ${ }^{53} \mathrm{La}$ articulación económica de la región en torno a la minería se reforzará aún más con el descubrimiento del mineral de plata de Chañarcillo en 1832. Si además consideramos que el auge minero implica una mayor circulación en torno al puerto de Coquimbo (en 1828 por ejemplo anclaron 100

49. «Carta de Ramón Freire a Exmo. Señor Director del Estado de Chile», Concepción, 14 de septiembre de 1820, AMH, vol. 51, s/f.

50. Véase, Bauer, Arnold, «Chilean Rural Labour in de Nineteenth Century», American Historical Review, vol. LXXVI, n. ${ }^{\circ}$ 4, Washington, DC, 1971.

51. The National Archives, Londres, Foreign Office (en adelante FO), 16/4; 16/11; 16/16; 16/18; 16/22.

52. Llorca-Jaña, Manuel, The British Textile Trade in South America in the Nineteenth Century, Nueva York, Cambridge University Press, 2012, p. 157.

53. Ibidem, p. 156. 
barcos) ${ }^{54}$ el objetivo de la visita fiscal resulta evidente. Como señala el ministro de $\mathrm{Ha}$ cienda, el comercio es «el jugo nutritivo que nutre las arcas fiscales», y la renta de aduanas «es, por su naturaleza, el barómetro que manifiesta el comercio i riqueza de la nación»;55 cuidar que este barómetro se encuentre en óptimas condiciones es fundamental para el interés del Estado.

\section{La década de 1830: configuración de la administración provincial en torno al desarrollo comercial}

Para la década de 1830 contamos con algunos presupuestos esporádicos que permiten reconstruir y seguir el pulso a la configuración y cambios de la administración provincial. En años previos al desarrollo de una estadística oficial estos documentos entregan datos sobre el número y las reparticiones provinciales.

CuAdro 2. Presupuesto de la provincia de Coquimbo, 1832 (en pesos corrientes)

\begin{tabular}{lcc}
\hline PODER EJECUTIVO & & \\
\hline Intendencia & $15,0 \%$ & 7.850 \\
Gobierno del Puerto & $2,6 \%$ & 1.368 \\
Subtotal & $17,6 \%$ & 9.218 \\
\hline PoDER JUDICIAL & & \\
\hline Juzgado de Letras & $4,6 \%$ & 2.400 \\
Juzgado de comercio & $0,4 \%$ & 200 \\
Subtotal & $5,0 \%$ & 2.600 \\
\hline ADMINISTRACIÓN DE HACIENDA & & \\
\hline Aduana y tesorerías unidas & $15,0 \%$ & 7.818 \\
Aduana del Huasco & $7,1 \%$ & 3.753 \\
Resguardo del Huasco & $7,5 \%$ & 3.944 \\
Aduana de Copiapó & $6,9 \%$ & 3.610 \\
Resguardo de Copiapó & $7,5 \%$ & 3.944 \\
Tesorería de Illapel & $0,2 \%$ & 98 \\
Factoría de tabacos & $12,7 \%$ & 6.671 \\
Administración de correos & $4,0 \%$ & 2.086 \\
Resguardos & $16,7 \%$ & 8.760 \\
Subtotal & $77,4 \%$ & 40.648 \\
TOTAL & $100 \%$ & 52.466 \\
\hline
\end{tabular}

FuENTE: Comisión General de Cuentas, 30 de mayo de 1832, firma Rafael Correa de Saa.

54. FO 16/6, fj. 116.

55. Memoria de Hacienda de 1839, en SCL, tomo XXVI, pp. 76-84. 
El primer presupuesto detallado con el que contamos es el de 1832. La organización y clasificación del gasto fiscal se organiza en torno a los poderes del Estado y por provincia.

Un primer aspecto a destacar es el elevado gasto destinado a las reparticiones de Hacienda; este cuadruplica el presupuesto de la administración ejecutiva de la provincia. Un segundo es que inclusive si contemplamos los gastos destinados a Defensa (3.728 pesos al Ejército y 9.611 pesos a la Marina), Hacienda se mantiene muy por encima. Esta constatación supone un cambio importante respecto a la década anterior, caracterizada por la precariedad de la administración y la preponderancia de la guerra (Defensa) en todos los ámbitos de gobierno (administración, finanzas públicas, estructuras sociales). ${ }^{56}$

La apertura e inserción de la economía chilena en el mercado internacional es una de las explicaciones del desarrollo institucional vinculado principalmente a las oficinas de aduana y los puertos, en este caso Coquimbo y Huasco.

En las postrimerías de la colonia, el comercio chileno había experimentado una creciente apertura producto de las medidas propulsadas por la monarquía española, pero el resultado fue la saturación del mercado interno, y la quiebra y ruina de muchos comerciantes locales. ${ }^{57}$ Las campañas militares de la independencia no afectaron directamente la producción de la región minera (el escenario del conflicto fue el centro sur del territorio), pero la desarticulación de la administración local sí afectó en la percepción de tributos. ${ }^{58}$

En 1811 se sancionó un decreto de libre comercio que abrió cuatro puertos al intercambio con las potencias extranjeras (Valdivia, Concepción, Valparaíso y Coquimbo). Esta medida generó mucha controversia ya que estuvo motivada por necesidades pragmáticas: incrementar las entradas fiscales desangradas producto de la guerra; y se aprobó pese a la oposición de los comerciantes. ${ }^{59}$ Tras la independencia hay una rearticulación de

56. Véase, López Taverne, Elvira, «La organización de la administración pública en una escala local: la provincia de Coquimbo en la década de 1820», Revista de Gestión Pública, vol. 5, n. ${ }^{\circ}$ 2, julio-diciembre, Santiago, 2016, pp. 187-218.

57. Sobre las dinámicas e implicancias de las reformas comerciales, económicas y fiscales borbónicas para los reinos americanos véase Delgado, Josep María, Dinámicas imperiales (1650-1796): España, América y Europa en el cambio institucional del sistema colonial español, Barcelona, Edicions Bellaterra, 2007; Delgado, Josep María, «La integración de Hispanoamérica en el mercado mundial (1797-1814)», Boletín Americanista, n. ${ }^{\circ} 31$, Barcelona, 1981, pp. 41-52; Marichal, Carlos, La bancarrota del virreinato. Nueva España y las finanzas del Imperio español, 1780-1810, Fondo de Cultura Económica, El Colegio de México, Fideicomiso Historia de las Américas, 1999; Marichal, Carlos, «Beneficios fiscales y costos del colonialismo: las remesas americanas a España 1760-1814», en Sánchez, Ernest, Luis Jáuregui y Antonio Ibarra (coord.), Finanzas y política en el mundo iberoamericano. Del Antiguo Régimen a las naciones independientes, México, Universidad Autónoma del Estado de Morelos, Instituto Mora, Facultad Economía UNAM, 2001, pp. 29-62. El rol crucial que pasa a ocupar Inglaterra en las relaciones comerciales con las nacientes repúblicas del Cono Sur ha sido estudiado por Manuel Llorca-Jaña, quien además demuestra que el volumen de exportación de mercancías inglesas a esta región fue mayor durante la primera mitad del siglo XIX, de allí su importancia estratégica, véase, Llorca-Jaña, Manuel, The British Textile..., cit., pp. 287-288.

58. Véase, Méndez, Luz María, La exportación minera en Chile 1800-1840. Un estudio de historia económica y social en la transición de la Colonia a la República, Santiago, Editorial Universitaria, 2004, p. 35.

59. La apertura comercial propulsada por las reformas administrativas borbónicas ya había generado una fuerte oposición de los comerciantes locales, que vieron arruinado su negocio al no poder competir con los 
las redes comerciales; el espacio dejado por la Metrópolis será ocupado rápidamente por Inglaterra, que desde estos años comienza a establecer relaciones económicas con Chile, forjando una dependencia que se mantendrá a lo largo del siglo XIX. ${ }^{60} \mathrm{Al}$ igual que durante la época colonial, la nueva configuración se caracterizará por la preponderancia y subordinación del comercio de importación y por la exigencia de la nueva economía dominante de metales preciosos.

Las exportaciones chilenas a Inglaterra consistirán en cobre, lana y cueros. Desde 1820 la demanda de cobre no cesa de aumentar, a tal punto que la producción nacional llega a constituir el $40 \%$ de la producción mundial en los años cincuenta. ${ }^{61} \mathrm{La}$ minería constituyó - y constituye hasta el presente - el rubro principal de las exportaciones chilenas, y desde la década de 1830, la fuerte demanda internacional por el metal rojizo incidió en el alza de su precio (entre 1815 y 1820 este se duplicó). El aumento de la producción, del volumen de exportación y el alza de su valor, se reflejó en el impacto del comercio de exportación en la base tributaria del país, al generar un porcentaje mayor de impuestos aduaneros. ${ }^{62}$

bajos costos de las mercancías que saturaron el mercado local. Véase el informe de Manuel de Salas, síndico del Tribunal del Consulado, «Representación hecha al Ministro de Hacienda don Diego de Gardogui por el síndico del Real Consulado de Santiago, sobre el estado de la agricultura, comercio e industria del Reino de Chile», en Escritos de Don Manuel de Salas y documentos relativos a él y a su familia, tomo I, Santiago, Imprenta Cervantes, 1910, p. 151; y Villalobos, Sergio, El comercio y la crisis colonial. Un mito de la Independencia, Santiago, Ediciones de la Universidad de Chile, 1968.

60. El comercio con Inglaterra no es algo nuevo, pero como señala Josep María Delgado, el fin del monopolio español trastoca la naturaleza de este intercambio: «Puede decirse que a finales del siglo XVIII, el comercio inglés espera el estallido de un conflicto que derribe definitivamente las barreras del monopolio español. Hasta 1808 la entrada de la manufactura inglesa en América se produce por dos caminos: escondida entre las importaciones norteamericanas o, como sucedería en Montevideo y Buenos Aires, a través de una ocupación temporal de alguna zona, que se aprovechaba para abastecerla de productos ingleses. La invasión francesa a España y el peligro de que ésta se extendiera a sus posesiones en América, junto a la llegada de las primeras noticias de movimientos insurreccionales de gran amplitud, ofreció a Gran Bretaña la posibilidad de actuar como defensora de su débil aliado y mediadora en sus discordias. Estos argumentos, justificadores de la intervención británica se esgrimirán contra la misma metrópoli cuando proteste del uso que sus aliados hacen de la amistad», Delgado, Josep María, «La integración de Hispanoamérica...», cit., p. 49.

El caso de Chile no es en ningún caso excepcional, sino parte de una política que desarrolló la gran potencia con todas las nuevas repúblicas hispanoamericanas, «Inglaterra, a cambio de una colaboración abierta con los insurrectos obtenía una serie de privilegios de tipo comercial que eliminaban la competencia de otros países en vías de industrialización sin el desgaste económico de mantener una estructura política y militar de dominación permanente, sólo a base de acciones muy concretas. De este modo, la manufactura británica lograría lo que nunca había logrado la española: convertirse en un artículo de consumo de la población indígena estableciendo una competencia ventajosa con los obrajes...», Delgado, Josep María, «La integración de Hispanoamérica...», cit., p. 51. Véase también Salazar, Gabriel, Mercaderes, empresarios y capitalistas..., cit., pp. 79-160. Véase también, Llorca-Jaña, Manuel y Juan Navarrete-Montalvo, «The Chilean Economy during the 1810-1830s and its Entry into the World Economy», Bulletin of Latin American Research, Oxford, 2016, pp. 354-369.

61. Cavieres, Eduardo, Comercio chileno y comerciantes ingleses 1820-1880. Un ciclo de historia económica, Valparaíso, Universidad Católica de Valparaíso, 1988, p. 63.

62. Méndez, Luz María, La exportación minera en Chile..., cit., p. 41. Según las cifras de la autora, entre 1800 y 1840 las exportaciones de cobre por vía marítima ascendieron a 1.659.403 quintales (76.333 toneladas), que en su totalidad se enviaron al exterior directamente desde los puertos nortinos (Coquimbo: $37 \%$ con 609.674 quintales; Copiapó: $21 \%$ con 348.820 quintales; Huasco: $40 \%$ con 666.310 quintales; y finalmente 
Respecto a las importaciones, desde Gran Bretaña se traían en enormes cantidades manufacturas y ropas de algodón, lana, lino y seda, «avalancha» que difícilmente podía ser asimilada por el mercado chileno. ${ }^{63}$

El siguiente presupuesto detallado con el que contamos corresponde al año 1840.

CuAdro 3. Presupuesto Provincia de Coquimbo, 1840 (en pesos corrientes)

\begin{tabular}{lrr}
\hline Intendencia & $15,9 \%$ & 8.262 \\
Juzgado de Letras & $4,6 \%$ & 2.400 \\
Aduana de Coquimbo & $37,5 \%$ & 19.479 \\
Aduana de Huasco & $15,3 \%$ & 7.958 \\
Aduana de Copiapó & $17,7 \%$ & 9.199 \\
Subtotal Aduanas & $70,6 \%$ & 36.636 \\
Administración de Correos & $4,2 \%$ & 2.157 \\
Instituto de Coquimbo & $7,6 \%$ & 3.960 \\
Casa de Moneda & $1,7 \%$ & 880 \\
Total & $100 \%$ & 51.895 \\
\hline
\end{tabular}

El análisis comparativo de este presupuesto respecto al anterior muestra que se mantiene un nivel de gasto similar, y que la administración de Hacienda es el principal destino de la inversión fiscal. Su estudio en detalle, por otra parte, permite reconstruir el organigrama burocrático de la provincia, ya que se enumeran todas las reparticiones, con listas de funcionarios y montos de salarios.

En el Ejecutivo se desempeñan el intendente, un secretario, dos oficiales y dos ayudantes, además de un ayudante mayor de artillería en el gobierno del puerto. En el ámbito judicial se mantiene un solo juez de letras. El despliegue mayor concierne a las oficinas de Hacienda: hay tres aduanas en la provincia. La principal es la Tesorería y Aduana de Coquimbo, que cuenta con 8 funcionarios y su resguardo con 18; la aduana de Huasco cuenta con 5 y 9 de resguardo; y la aduana de Copiapó con 7 y 11 de resguardo. La administración de correos es otra institución con un despliegue territorial importante; cuenta con oficinas en Sotaquí, Illapel, Coquimbo, Combarbalá, Vallenar y Copiapó. El Instituto de Coquimbo también figura en el presupuesto, con tres profesores, un maestro de primeras letras, tres ayudantes, un inspector y un portero. Y en último lugar figura la Casa de Moneda, con un oficial interventor y un portero, aunque sabemos que esta institución no se encontraba operativa.

La asignación de ingentes recursos a las oficinas de aduana y a la administración portuaria, así como el hecho de contar con una plana de funcionarios mayor, responde a las

\footnotetext{
Valparaíso con 34.599 quintales), p. 36. Hay que señalar que estas cifras no contemplan los elevados niveles de contrabando.

63. Cavieres señala como ejemplo el año 1835, en el que las importaciones representaron el cuádruple de la exportación de cobre durante los años 1820-1835. Cavieres, Eduardo, Comercio chileno y comerciantes..., cit.
} 
directrices económicas de la década. Los años 1830 se caracterizan por un desarrollo comercial importante, en particular del comercio exterior, lo que redunda en un constante aumento de los ingresos fiscales. En esta lógica que se retroalimenta, la renta de aduanas es la que contribuye con mayores ingresos al fisco, el ya mencionado barómetro de la riqueza nacional. ${ }^{64}$

GRÁFICO 1. Evolución del ingreso total e ingreso de aduanas, 1830-1839 (en pesos corrientes)

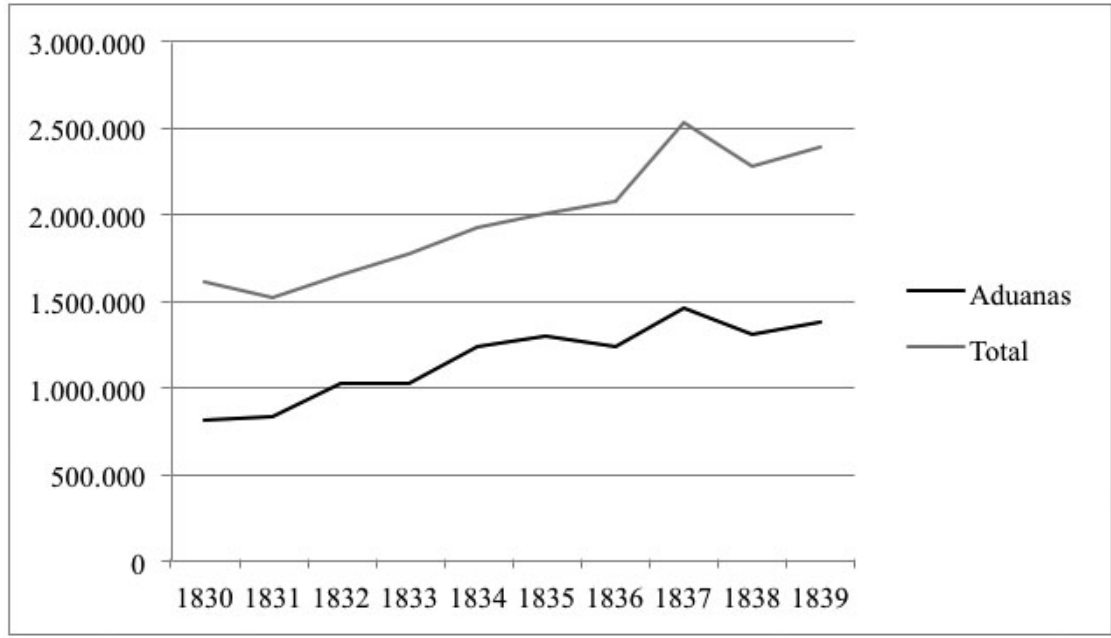

Fuente: Resumen de la Hacienda Pública de Chile, pp. 5-7, MH 1834, 1835, 1836 y 1839.

El gráfico ilustra la tendencia ya mencionada: las entradas de aduanas son el sostén del erario público y su aumento o disminución incide de manera directa en el total de la recaudación fiscal. Esta configuración se mantendrá en el tiempo, afianzándose la dependencia respecto del comercio exterior.

Ahora bien, aunque las cifras son auspiciosas, la consigna respecto a la inversión fiscal es la austeridad. Se busca un equilibrio de las rentas, y a la menor señal de incremento del gasto público suenan las alarmas. En este período se sientan las bases del sistema económico conservador y las reformas son numerosas, aunque todavía no se observa el desarrollo y despliegue de la década siguiente, cuando el notorio crecimiento de los ingresos permita también una inversión y diversificación mayor del gasto fiscal. ${ }^{65}$

64. Memoria de Hacienda de 1839 , p. 80.

65. López Taverne, Elvira, El proceso de construcción estatal en Chile. Hacienda pública y burocracia (18171860), Santiago, Centro de Investigaciones Diego Barros Arana/DIBAM, 2014, p. 127. 


\section{Consideraciones finales}

Si nos fijamos en los presupuestos nacionales, entre 1833-1839 los sueldos de la burocracia civil se mantendrán constantes. Tal como se desprende del análisis comparativo de los presupuestos provinciales, la atención está puesta en la organización institucional más que en su desarrollo; el objetivo es establecer y reglamentar la planta civil.

El estudio de la visita fiscal y los datos con que contamos para estos años revelan que la administración y el gobierno de la provincia se articularán en torno al comercio internacional. La producción minera y su exportación son el centro en torno al cual se produce el desarrollo institucional de la región, lo que se refleja en la predominancia de las instituciones como la aduana y el puerto. La predominancia del presupuesto del departamento de Hacienda por sobre el de Defensa es indiscutible.

Asimismo, el análisis de la organización institucional y burocrática en Coquimbo revela el lugar representativo que juega la provincia en la implementación de las directrices que guían la política gubernamental y fiscal del régimen conservador. La gran cantidad de yacimientos mineros hacen de esta región uno de los territorios más ricos del país, por lo cual es clave reforzar el control sobre sus recursos. Así, la visita fiscal será un instrumento para implementar el centralismo en la región. Las reformas propuestas por el visitador apuntan a mejorar la eficiencia, indispensable para el desarrollo comercial, pero entre líneas se lee un ajuste desde el gobierno central, que utiliza la ocasión para remover de sus funciones a los empleados que no son adictos al nuevo régimen. Por otra parte, estas reformas se verán apoyadas por el nuevo marco jurídico sancionado en la constitución de 1833, que otorga el manejo de la economía y de los recursos al poder Ejecutivo, acabando con cualquier conato de autonomismo.

La relación entre la actividad minera nortina y el control social ha sido un tema bastante trabajado por la historiografía social. ${ }^{66} \mathrm{La}$ formación del Estado, que en los territorios alejados constituye, en palabras de Milton Godoy, una entelequia, es un proceso de largo aliento. En los campamentos mineros, perdidos en el desierto, la institucionalidad se confunde con las estructuras tradicionales de control social y con el rostro de los empresarios mineros, quienes cooptan los medios de control social como los cuerpos de policía en defensa de sus propios intereses. ${ }^{67}$

Por último, resulta interesante observar que el modelo de organización administrativo que se configura en estos años será foco de crítica durante las guerras civiles de mediados de siglo. En las regiones nortinas, justamente donde el gobierno local se articuló en

66. Véase, Grez, Sergio, De la «regeneración del pueblo» a la buelga general. Génesis y evolución bistórica del movimiento popular en Chile (1810-1910), Santiago, Centro de Investigaciones Diego Barros Arana, 1998; Illanes, María Angélica, «Azote, salario y ley. Disciplinamiento de la mano de obra en la minería de Atacama (1817-1850)», Proposiciones, n. ${ }^{\circ}$ 19, Santiago, 1990, pp. 90-122; Illanes, María Angélica, Chile Des-centrado. Formación socio-cultural republicana y transición capitalista (1810-1910), Santiago, Lom Ediciones, 2003.

67. Véase, Godoy, Milton «La ley es una moneda en el desierto. Agentes estatales, empresarios mineros y conflictos de intereses en la periferia del Estado nacional chileno: Taltal 1850-1900», Estudios Atacameños. Arqueología y Antropología Surandinas, n. ${ }^{\circ}$ 52, San Pedro de Atacama, 2016, pp. 31-48. 
torno al desarrollo comercial y a la producción minera, los propietarios se levantarán contra el gobierno central defendiendo un discurso regionalista que propugnaba por una descentralización política y administrativa, que implicaba medidas de carácter económico como disminuir la tributación minera, un control más directo de sus recursos y políticas de fomento. ${ }^{68}$

El gobierno saldrá airoso de los dos conflictos de mediados de siglo (1851 y 1859), y aunque su corolario implicará transformaciones en el escenario político, la estructura burocrática e institucional altamente centralizada que se había configurado en las décadas anteriores se mantendrá vigente. La matriz económico-productiva no sufre mayores variaciones, ni la estructura tributaria, acentuándose inclusive la dependencia respecto del comercio exterior. ${ }^{69} \mathrm{Si}$ algo cambia, es que se pone fin a las décadas de austeridad fiscal; el Estado comienza a invertir significativamente, en educación, obras públicas, beneficencia, entre otros, y se crea un marco jurídico para regular las finanzas.

\section{Bibliografía}

\section{Fuentes}

Archivo Nacional de Chile, Fondo Intendencia de Coquimbo A.N.I.C., vols. 7, 13, 14.

Archivo Nacional de Chile, Fondo Ministerio de Hacienda A.M.H., vols. 28, 46, 51.

Archivo Nacional de Chile, Fondo Municipalidad de Coquimbo, vol. 2.

The National Archives, Foreign Office, 16/4; 16/11; 16/16; 16/18; 16/22.

Bello, Andrés, El Araucano, n. ${ }^{\circ}$ 140, 141 y 142 (editorial), en Sagredo, Rafael (ed.), Textos fundamentales. Construcción del Estado en Cbile, Andrés Bello, Santiago, Cámara Chilena de la Construcción, Pontificia Universidad Católica de Chile, Biblioteca nacional, Biblioteca Fundamentos de la Construcción de Chile, 2010.

De Salas, Manuel, Escritos de Don Manuel de Salas y documentos relativos a él y a su familia, tomo I, Santiago, Imprenta Cervantes, 1910.

Gay, Claudio, «Questionnaires et réponses sur la situation des provinces du Chili adrésées par Claude Gay aux Gouverneurs», Boite 1: Notes et documents divers, dossier vert: 1841, Mss 096/3/1 à 10, Archives de la Société d'études archeologiques et scientifiques de Draguignan.

Giliss, James M., The U.S. Naval Astronomical Expedition to the Southern Hemisphere During the Year 1849-'50-'51-'52, Washington, A.O.P. Nicholson Printer, 1855.

Letelier, Valentín, Sesiones de los Cuerpos Legislativos de la República de Chile 1811 a 1845. vol. XXVI, Santiago, Imprenta Cervantes, 1887-1908.

Philippi, Rudolph, Viaje al desierto de Atacama, Santiago, Cámara Chilena de la Construcción, Pontificia Universidad Católica de Chile, Biblioteca Nacional, 2008 [1860].

68. Véase, Fernández Abara, Joaquín, Regionalismo, liberalismo y rebelión. Copiapó en la Guerra Civil de 1859, Santiago, Ril Editores, Universidad Finis Terrae, 2016.

69. Véase, Ortega, Luis, Chile en la ruta al capitalismo. Cambio, euforia y depresión 1850-1880, Santiago, DIBAM, Ediciones LOM, Centro de investigaciones Diego Barros Arana, 2005. 


\section{Bibliografía secundaria}

Abara, Joaquín, Regionalismo, liberalismo y rebelión. Copiapó en la Guerra Civil de 1859, Santiago, Ril Editores, Universidad Finis Terrae, 2016.

Arias, Karina, «Revisión de las estructuras político-administrativas territoriales en el Chile del siglo XIX», Revista Universum, vol. 1, n. ${ }^{\circ} 25$, Talca, 2010, pp. 44-59.

Barbier, Jacques, «Élite and Cadres in Bourbon Chile», The Hispanic American Historical Review, vol. 52, n. ${ }^{\circ}$ 3, Washington DC, 1972, pp. 416-435.

Barros Arana, Diego, El doctor don Rodolfo Amando Philippi. Su vida y sus obras, Santiago, Imprenta Cervantes, 1904.

Bauer, Arnold, «Chilean Rural Labour in de Nineteenth Century», American Historical Review, vol. LXXVI, n. ${ }^{\circ}$ 4, Washington, DC, 1971.

Bilot, Paulina, «Las causas por torcida administración de justicia: mirada letrada hacia prácticas legas en Chile, 1824-1875», SudHistoria, n. ${ }^{\circ}$ 5, julio-diciembre, Chile, 2012, pp. 99-123.

Carmagnani, Marcello, El salariado minero en Chile colonial. Su desarrollo en una sociedad provincial: el Norte Chico 1690-1800, Santiago, Editorial Universitaria, 1963.

—, Les mécanismes de la vie économique dans une société coloniale, le Chili: 1680-1830, París, S.E.V.P.E.N., 1973.

-, Comercio chileno y comerciantes ingleses 1820-1880. Un ciclo de historia económica, Valparaíso, Universidad Católica de Valparaíso, 1988.

Cavieres, Eduardo, La Serena en el siglo XVIII. Las dimensiones del poder local en una sociedad regional, Valparaíso, Ediciones Universitarias de Valparaíso, 1993.

Cartes, Armando, «Un gobierno de los pueblos...». Relaciones provinciales en la independencia de Chile, Valparaíso, Ediciones Universitarias de Valparaíso, 2014.

Cobos, María Teresa, «El régimen de Intendencias en el Reino de Chile. Fase de implantación 1786-1787», Revista Chilena de Historia del Derecho, n. ${ }^{\circ}$ 7, Santiago, 1978, pp. 85-106.

Collier, Simon, Ideas y política de la independencia chilena, 1808-1833, Santiago, Fondo de Cultura Económica, 2012.

Delgado, Josep María, «La integración de Hispanoamérica en el mercado mundial (1797-1814)», Boletín Americanista, n. ${ }^{\circ}$ 31, Barcelona, 1981, pp. 41-52.

-, Dinámicas imperiales (1650-1796): España, América y Europa en el cambio institucional del sistema colonial español, Barcelona, Edicions Bellaterra, 2007.

Enríquez, Lucrecia, «Los jueces diputados y los distritos judiciales borbónicos en Chile (17861818)», Revista Chilena de Derecho, vol. 43, n. ${ }^{\circ}$ 2, Santiago, 2016, pp. 643-668.

—, «Reformar para uniformar. La implantación del régimen de Intendencias en Chile, en Bertrand, M., F., Andújar y T. Glesener (eds.), Gobernar y reformar la Monarquía. Los agentes políticos y administrativos en España y América, siglos XVI-XIX, Valencia, Albatros, 2017, pp. 287-303.

Estefane, Andrés, «Un alto en el camino para saber cuántos somos. Los censos de población y la construcción de lealtades nacionales. Chile, siglo XIX», Historia, n. ${ }^{\circ} 37$, vol. 1, enero-junio, Santiago, 2004, pp. 33-59.

Fernández, Joaquín, Regionalismo, liberalismo y rebelión. Copiapó en la Guerra Civil de 1859, Santiago, Ril Editores, Universidad Finis Terrae, 2016.

Godoy, Milton «La ley es una moneda en el desierto. Agentes estatales, empresarios mineros y conflictos de intereses en la periferia del Estado nacional chileno: Taltal 1850-1900», Estudios Atacameños. Arqueología y Antropología Surandinas, n. ${ }^{\circ}$ 52, San Pedro de Atacama, 2016, pp. 31-48. 
Grez, Sergio, De la «regeneración del pueblo» a la buelga general. Génesis y evolución histórica del movimiento popular en Chile (1810-1910), Santiago, Centro de Investigaciones Diego Barros Arana, 1998.

Heise, Julio, Años de formación y aprendizaje políticos 1810-1833, Santiago, Editorial Universitaria, 1978.

Hurtado, Carlos, Concentración de población y desarrollo económico. El caso chileno, Santiago, Universidad de Chile, 1966.

Illanes, María Angélica, «Azote, salario y ley. Disciplinamiento de la mano de obra en la minería de Atacama (1817-1850)», Proposiciones, n. ${ }^{\circ}$ 19, Santiago, 1990, pp. 90-122.

-, Chile Des-centrado. Formación socio-cultural republicana y transición capitalista (1810-1910), Santiago, Lom Ediciones, 2003.

Llorca-Jaña, Manuel, The British Textile Trade in South America in the Nineteenth Century, Nueva York, Cambridge University Press, 2012.

Llorca-Jaña, Manuel y Juan Navarrete-Montalvo, «The Chilean Economy during the 1810-1830s and its Entry into the World Economy», Bulletin of Latin American Research, Oxford, 2016, pp. 354-369.

López Taverne, Elvira, El proceso de construcción estatal en Chile. Hacienda pública y burocracia (1817-1860), Santiago, Centro de Investigaciones Diego Barros Arana/DIBAM, 2014.

-, «La organización de la administración pública en una escala local: la provincia de Coquimbo en la década de 1820», Revista de Gestión Pública, vol. 5, n. ${ }^{\circ}$ 2, julio-diciembre, Santiago, 2016, pp. 187-218.

Marichal, Carlos, La bancarrota del virreinato. Nueva España y las finanzas del Imperio español, 1780-1810, Fondo de Cultura Económica, El Colegio de México, Fideicomiso Historia de las Américas, 1999.

—, «Beneficios fiscales y costos del colonialismo: las remesas americanas a España 1760-1814», en Sánchez, Ernest, Luis Jáuregui y Antonio Ibarra (coord.), Finanzas y política en el mundo iberoamericano. Del Antiguo Régimen a las naciones independientes, México, Universidad Autónoma del Estado de Morelos, Instituto Mora, Facultad Economía UNAM, 2001, pp. 29-62.

Méndez, Luz María, La exportación minera en Chile 1800-1840. Un estudio de historia económica y social en la transición de la Colonia a la República, Santiago, Editorial Universitaria, 2004.

Ortega, Luis, Chile en la ruta al capitalismo. Cambio, euforia y depresión 1850-1880, Santiago, DIBAM, Ediciones LOM, Centro de Investigaciones Diego Barros Arana, 2005.

Ossa, Juan Luis, «La actividad política de Francisco Antonio Pinto: 1823-1828. Notas para una revisión biográfica», Historia, n. ${ }^{\circ}$ 40, vol. 1, enero-junio, Santiago, 2007, pp. 91-128.

Pérez Rosales, Vicente, Ensayo sobre Chile. Santiago, Imprenta El ferrocarril, 1959.

Sagredo, Rafael, José Ignacio González y José Compan, La política en el espacio. Atlas histórico de las divisiones político-administrativas de Chile, 1810-1940, Santiago, Pontificia Universidad Católica de Chile Instituto Geográfico Militar, Centro de Investigaciones Diego Barros Arana DIBAM, 2016.

Salazar, Gabriel, Mercaderes, empresarios y capitalistas (Chile, siglo XIX), Santiago, Editorial Sudamericana, 2009.

Sanhueza, María Carolina, «La primera división político-administrativa de Chile, 1811-1826», Historia, vol. 41, n. ${ }^{\circ}$ 2, Santiago, 2008, pp. 447-493.

Villalobos, Sergio, El comercio y la crisis colonial. Un mito de la Independencia, Santiago, Ediciones de la Universidad de Chile, 1968. 